by more than $70 \%$. Although the number of foreign students dropped in the years after the 2001 terrorist attacks, it has risen in recent years.

The trend in domestic students this year was also apparent at the University of Illinois at Urbana-Champaign, another top-five school for science and engineering doctorates. Domestic applications rose by $25 \%$, whereas foreign ones rose by $13 \%$.

The Massachusetts Institute of Technology in Cambridge, the third-largest awarder of science and engineering doctorates, received 9,475 doctoral applications this year, a $6 \%$ increase. During the previous four years, the growth in applications had held steady at about $4 \%$ a year.

Other universities, such as the University of Toronto in Canada, the Johns Hopkins University in Baltimore, Maryland, and Duke University in Durham, North Carolina, have also reported large rises in graduate applications, says Stewart.

Although graduate deans view the numbers as a positive sign, most universities are unlikely to expand the number they enrol because they lack the resources to support more graduate students. The application surge "is happening right at the same time that most universities are undergoing the most serious financial constraints they have faced in decades and decades", says Stewart.

Richard Monastersky

initially guided by proteins and RNA found in the egg, with control eventually passing to DNA in the nucleus. This transfer of power occurs in humans when the embryo has reached four to eight cells; but in mice it happens at the two-cell stage, and this mismatch may disrupt development.

Furthermore, the nuclear genome may have difficulty communicating with energy-producing structures called mitochondria - which are inherited directly from the mother, through the egg - from distantly related species.

If researchers can find the reason why some hybrid embryos stop developing, they might be able to circumvent those roadblocks by altering the expression of specific genes, says cell biologist Jose Cibelli of Michigan State University in East Lansing.

Meanwhile, there may be other ways to reprogram a cell with a different species' DNA, notes embryologist Anthony Perry at the RIKEN Center for Developmental Biology in Kobe, Japan. "Is there really only one path that will give you a pup? Surely the answer is no," he says. "It's too early to write off interspecies hybrids." Heidi Ledford

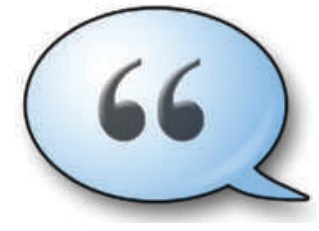

HAVE YOUR SAY

Comment on any of our news stories, online.

www.nature.com/news

\title{
'Experiments of concern' to be vetted online
}

\section{Expert panel to offer advice on science with bioterror applications.}

What do you do if you have a great idea for an experiment, but are worried that the results could enable a potential biological weapon?

Soon you will be able to ask a panel of experts for advice through a website being developed at the University of California, Berkeley.

Spearheaded by Stephen Maurer of the Goldman School of Public Policy and the Boalt Law School, the website is part of a suite of measures he has developed with scientists and public-policy experts to minimize the risks of biology research being misused.

The website, expected to begin operating by the end of March, will provide biologists with advice about 'dual-use research' or 'experiments of concern' - research with innocent goals that could inadvertently arm terrorists.

Scientists will be able to enter information about proposed experiments, each of which will be reviewed by a different panel of three experts. The panels will include at least one security expert and one biologist. They

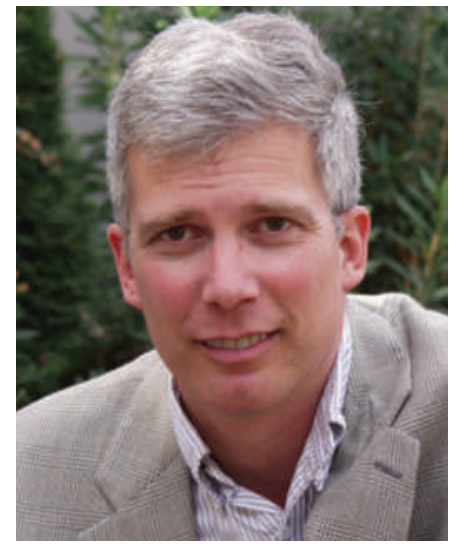

Stephen Maurer: giving advice on tap. influenza virus and submitted their paper to Science in 2005, US government officials and the National Science Advisory Board for Biosecurity (NSABB) were consulted about the work. At the behest of the NSABB, Science ran an editorial explaining why it had published the work - even though the paper was in press by the time the advisory board made its request (see Nature 437, 794; 2005). The new portal is designed to provide feedback before work begins, so such problems don't arise.

"It will be a place where people can ask questions, and other people can learn from those questions, so they don't have to ask them," says Michael Imperiale, a virologist and immunologist at the University of Michigan, Ann Arbor, who is a member of the NSABB.

Some information about the submitted experiments will be displayed on the website, although Maurer says reasonable confidentiality measures will be undertaken, such as holding back proprietary information until the work is published.

will deliver a verdict on whether the work raises any security concerns, and if so, how those concerns might be addressed. The entire process should take about two weeks, says Maurer.

Maurer has lined up experiments to beta-test the site and, if those go well, the site could open for business as early as April. The portal is supported by the Carnegie Corporation of New York, a philanthropic funding body.

Experiments of concern have long troubled scientists and policy-makers, not least because most security reviews of such experiments occur at a very late stage - when the work is already finished and ready to publish.

For example, when scientists reconstructed the genome of the 1918
Maurer admits that the portal's success will depend on how many scientists use it. But he is optimistic because the idea came from the community that will use it, and many scientists have already agreed to serve as expert reviewers.

"There is an instinct in the community that if you think you're talking about an experiment of concern, you should ask someone - but biosecurity people are scarce on the average campus," he says. The portal is designed to be a help, rather than a burden, in these situations. "People have enough layers of paperwork in their lives," says Maurer. "The idea is to make this as painless as possible."

Erika Check Hayden

Experiments of concern portal: http://tinyurl. com/bccenu. 